International Journal of Automotive and Mechanical Engineering

ISSN: 2229-8649 (Print); ISSN: 2180-1606 (Online)

Volume 15, Issue 2 pp. 5308-5325 June 2018

(C) Universiti Malaysia Pahang, Malaysia

DOI: https://doi.org/10.15282/ijame.15.2.2018.12.0409

\title{
Numerical Assessment of a New Hydro-Pneumatic Suspension System for Motorcycles
}

\author{
A. Martini ${ }^{1,2, *}$, G. Bellani ${ }^{1,3}$ and C. Fragassa ${ }^{1,2}$ \\ ${ }^{1} \mathrm{DIN}$ - Department of Industrial Engineering \\ University of Bologna, V. le del Risorgimento 2, 40136 Bologna, Italy \\ *E-mail: alberto.martini6@unibo.it \\ Phone: +390543374440 \\ ${ }^{2}$ CIRI - Advanced Applications in Mechanical Engineering and Materials Technology \\ University of Bologna, V.le del Risorgimento 2, 40136 Bologna, Italy \\ ${ }^{3}$ CICLOPE Laboratory - Center for International Cooperation in Long Pipe Experiments \\ University of Bologna, V. Fontanelle 40, 47121 Forlì, Italy
}

\begin{abstract}
This work investigates an innovative hydro-pneumatic suspension system that was recently developed for possibly enhancing the performance of wheeled road vehicles, particularly motorcycles. The device exhibits a highly non-linear behavior, and in particular a strongly regressive spring rate, due to its architecture (featuring a hydropneumatic spring and a coil spring arranged in series). Multibody models are implemented and simulated for a preliminary assessment of its actual benefits and/or drawbacks with respect to common suspension systems. As a starting point of the research, this work focuses on the in-plane dynamics, and in particular on a condition of straight running at constant speed. The load fluctuations on the rear wheel (grip) as well as the velocity of the suspended mass (comfort) under different road inputs at various speeds are analyzed. The numerical results confirm the hydro-pneumatic suspension system as a promising device.
\end{abstract}

Keywords: Hydro-pneumatic spring; non-linear stiffness; regressive suspension; motorcycle dynamics.

\section{INTRODUCTION}

Suspension systems are essential for controlling the dynamic response of wheeled vehicles [1-6], hence affecting also safety [6-8] and energy efficiency [9, 10]. New designs are constantly proposed for their implementation: the use of innovative passive components, like inerters, appears promising [11, 12]; semi-active systems can be adopted to modify their geometry [13] or other characteristic parameters [14], thus affecting the suspension behavior during motion; active suspensions, although having non-negligible energy requirements, can directly control the vehicle response $[15,16]$.

As for motorcycles, suspensions are of primary importance for both the vehicle performance (i.e. tire-road contact, stability and trim of motorcycle under various riding conditions) and the riding comfort (i.e. isolation of the sprung mass from the roadinduced vibrations) [17-20]. These two characteristics are generally conflicting, since stiffer suspensions are normally required for higher chassis stability under dynamic loads (acceleration, breaking and cornering), whereas softer spring rates are normally associated with comfort. For racing motorcycles the former aspect is typically 
preponderant. Conversely, for street motorcycles like high-performance naked bikes and roadsters both factors are relevant, and a proper compromise is required. As for road bikes, another strict constraint on the design of a conventional suspension with fixed spring rate(s) is given by the large load variation related to tandem riding with respect to single-rider condition, since the spring rate is mainly determined by the load capacity needed to accommodate two riders and the associated dynamic loads.

Numerous solutions have been developed for the design of both rear and front suspensions of motorcycles, in order to achieve a convenient trade-off between performance and comfort. Typical examples of passive suspension implementations include linkages [21, 22] or eccentric mechanisms [23], which permit to tune the forcedisplacement characteristic of the suspension, e.g. for achieving progressive behavior. Studies on front/rear interconnected suspensions for optimizing the motorcycle pitch can be found in the literature $[24,25]$. Semi-active suspensions characterized by controllable damping, e.g. by using electro-hydraulic valves [26] or magnetorheological fluids [27], have been also investigated. Moreover, additional devices for easily adjusting the static sag/load capacity, acting together with the suspensions, have been proposed $[28,29]$.

A new hydro-pneumatic suspension system for wheeled road vehicles, and in particular for motorcycles, has been recently developed [30, 31]. Its most innovative feature is the presence of a hydro-pneumatic spring arranged in series with a coil spring as shown in Figure 1 (a). The device is characterized by a strongly regressive spring rate (i.e. reducing while increasing deflection as in Figure 1(b)), thus providing a stiffer suspension for small displacements, and becoming softer as displacement (and hence load) increases. Furthermore, hydraulic preload can be easily adjusted, thus efficiently increasing the overall load capacity of the suspension. Therefore, the device is expected to provide several benefits with respect to conventional suspensions. It is expected to improve vehicle performance while preserving or enhancing riding comfort.
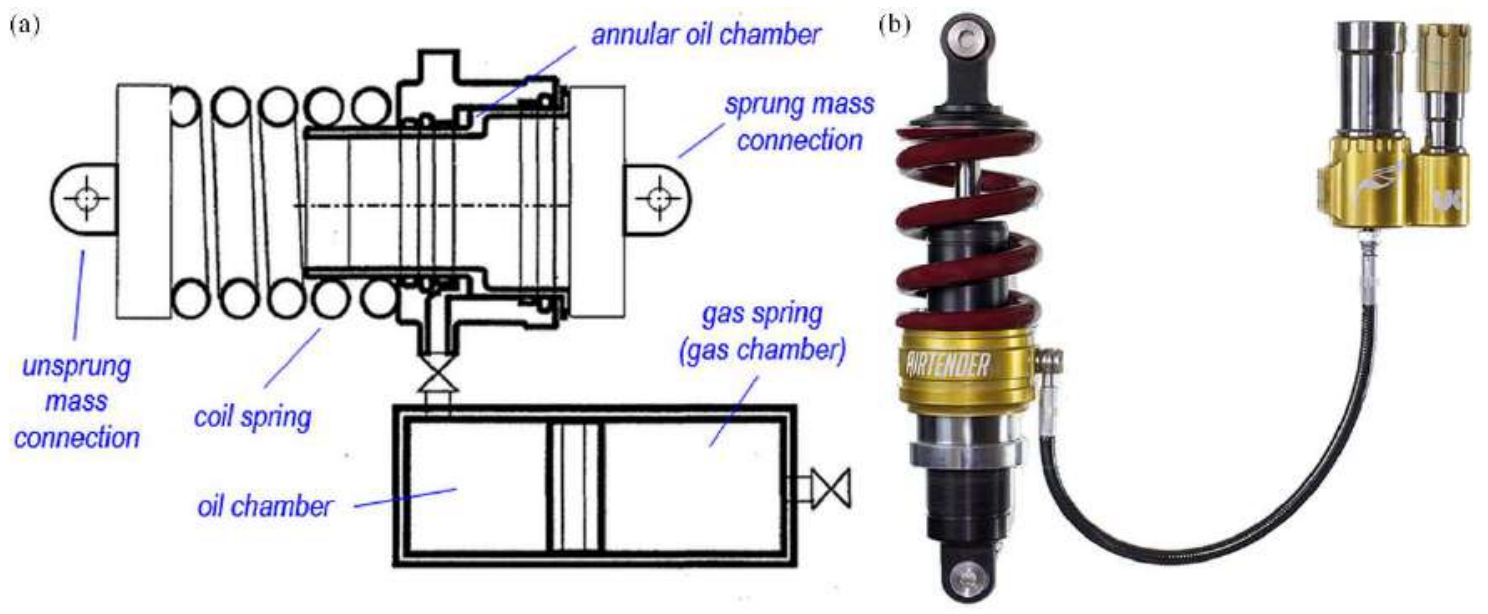

Figure 1. Hydro-pneumatic suspension (a) schematic drawing and (b) prototype.

This work aims at assessing through numerical simulations the actual advantages and drawbacks of the innovative hydro-pneumatic device, when adopted as rear suspension in a high-performance naked bike, with respect to a conventional suspension system (i.e. linear spring-rate with mechanical preload). The goal is to compare the in-plane dynamics of a motorcycle featuring the hydro-pneumatic suspension with that of an identical vehicle equipped with a standard suspension, in 
terms of both comfort and tire-road contact parameters. The paper focuses on simulations of the motorcycle in straight running at constant velocity, for different speeds and various road inputs.

Reduced models, such as the so-called quarter-car models, typically characterized by only two translational degree of freedom, are frequently exploited to investigate the behavior of suspension systems $[32,33]$. However, because of the strong non-linearities introduced by the new device, such models are not considered suitable for the desired analyses. Instead, complete multibody models of the motorcycle are developed to properly capture the full (non-linear) dynamic response of the system [3437]. Two planar multibody models (one for each suspension system) are implemented and simulated. The assumption on planar behavior is acceptable for the test conditions of interest, since in-plane and out-of-plane motions can be considered as decoupled in straight running [17, 20, 38]. A simplified rider (namely a rigid body attached to the sprung mass) is also considered; indeed, the rider's motion is expected to be relevant primarily for acceleration/breaking and cornering maneuvers [39, 40]. Furthermore, since the goal of this work is to isolate the effects of the elastic part of the suspension, only linear shock absorbers are considered in the present simulation, thus neglecting more complex damping characteristic curves. Finally, since the focus is on the comparative performance of the two suspensions, a simplified tire model is preferred rather than more complex ones [41-43].

The simulation results are primarily analyzed in terms of load fluctuations on the rear wheel and velocity of the suspended mass under different road inputs at various speeds. These quantities are typically used as quantitative indicators of tire-road contact (grip) and comfort, respectively, and can be easily extracted from both simulations and road tests. The paper is organized as follows. The second section provides details on the hydro-pneumatic device and describes the numerical models and the simulated test conditions adopted for the investigation. In the third section, the most relevant results of the simulations are reported and discussed. The final section draws the conclusion.

\section{METHOD AND MATERIALS}

\section{Hydro-Pneumatic Suspension System}

The patented system [30] is made by a hydro-pneumatic spring and a coil spring arranged in series as shown in Figure 1. The hydro-pneumatic spring is composed of a gas spring and an oil circuit that transmits the elastic force to the coil spring (and vice versa). Since the gas spring preload is much higher than the preload of the coil spring, only the coil spring undergoes deflection for small displacements of the suspension (Figure 2). Conversely, for larger values of displacement, the equivalent stiffness of the suspension is determined by the contribution of both springs. Due to energy dissipation in the hydro-pneumatic circuit, the load/deflection characteristic curve exhibits a clear non-linear behavior, and in particular a hysteresis loop (Figure 2). With such arrangement, the effective spring rate depends on the stroke: for small displacements around the static load the suspension is stiff (high resonance frequency), which is normally associated with high chassis stability but low comfort on bumpy roads. However, in the present setup, as the displacement increases, the overall spring-rate decreases as soon as the load exceeds the hydraulic preload. Hence, in this case the resonance frequency around the equilibrium point does not represent the dynamics of the suspension. 
(b)
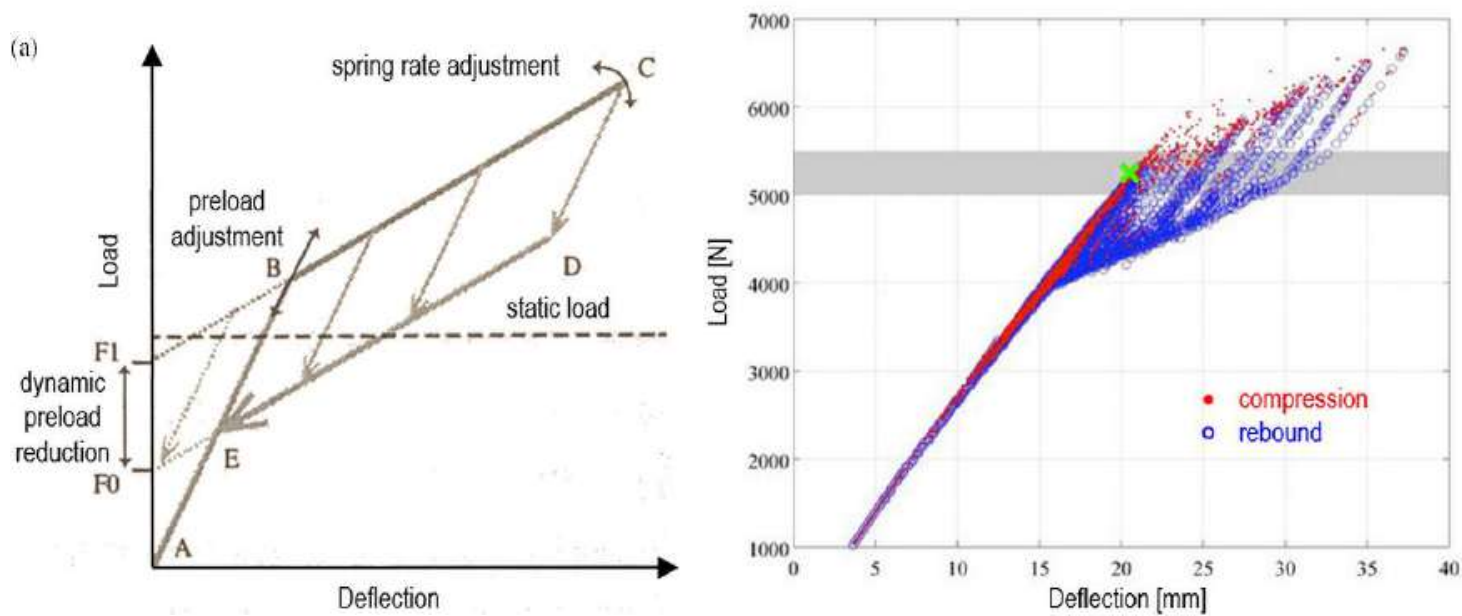

Figure 2. Load/deflection diagram of the hydro-pneumatic suspension from (a) qualitative trend and; (b) experimental curve.

Another interesting feature to investigate is the effect of the hydraulic preload on the riding properties, as this can be easily varied during riding by introducing or removing oil from the oil chamber with an external supply (not shown here). By varying the hydraulic preload, the point B on the graph shown in Figure 2 (a) can be moved up following the slope A-B (which depends on the stiffness of the coil-spring). This allows the rider to increase the overall load capacity when the static load is varied (for example when riding with a passenger) without affecting the spring rate. In this work, the focus is only on single rider condition and on the effect of hydraulic preload on riding properties.

\section{Numerical Multibody Models}

Rigid-body models of a complete motorcycle are developed within a commercial software environment (namely MSC ADAMS, which adopts a Lagrangian formulation for the equations of motion) and simulated by using the software internal solver. Two different multibody models are implemented, one for the conventional suspension system, the other for the hydro-pneumatic suspension system. The former (referred to as $S T$ hereafter) is a 5 degrees-of-freedom (DOF) planar model having three rigid bodies connected with joints modelled as kinematic pairs. The sprung mass, which consists of the motorcycle frame assembly and the rider (considered as a passive body rigidly connected to the frame) is constrained to a vertical plane by means of a planar joint. Hence, three DOFs describe its motion on the vertical plane (i.e. horizontal and vertical translations and pitch motion). The fourth DOF is associated with the rotation of the swing-arm, which is connected to the frame by means of a revolute joint. The fifth DOF describes the translation of the front fork, constrained to the frame with a cylindrical joint (on which a null rotation is imposed). The corresponding generalized coordinates $\left(q_{i}, i=1, . ., 5\right)$ are reported in Figure 3.

Both the front and the rear suspension systems are modelled by using lumped stiffness and damping parameters with constant values (respectively, $K_{s f}$ and $C_{s f}$ for the front fork, $K_{s r}$ and $C_{s r}$ for the swing-arm). Contact between each tire and road is modelled by means of a unilateral single-point visco-elastic force, hence taking into 
account possible wheel lift-off. It is modelled as a spring-damper characterized by constant stiffness and damping parameters, $K_{t f(r)}$ and $C_{t f(r)}$ respectively, which provides null force when wheel and road are not in contact, i.e. when the distance between its connecting points becomes smaller than the tire radius. The road profile exciting the vehicle dynamics is imposed independently on each wheel as a vertical displacement input function. This allows simulating the time delay between the two input displacements, which depends on the motorcycle actual speed.

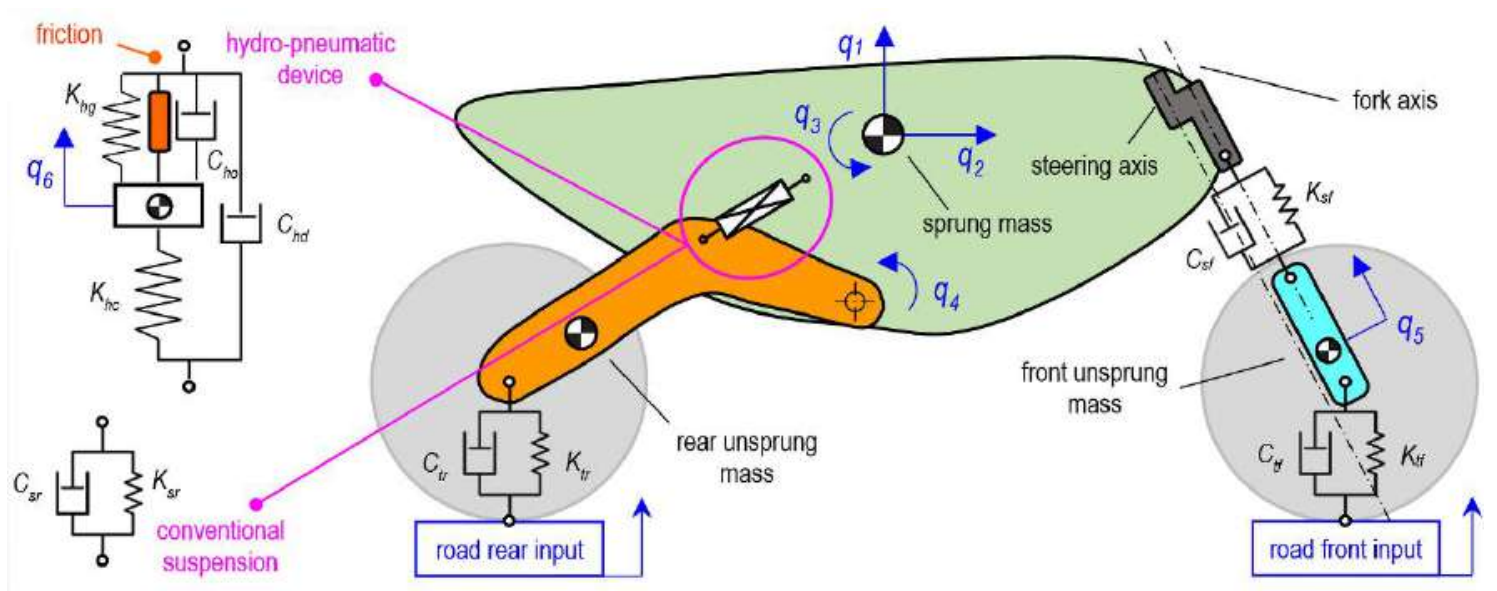

Figure 3. Schematics of the motorcycle multibody models.

In the second model (referred to as $A T$ hereafter), the rear suspension is replaced by the hydro-pneumatic device (Figure 3), connected to the frame and to the swing-arm by means of cylindrical and spherical joints, respectively. It consists of three rigid bodies constrained by means of two prismatic joints. An additional DOF $\left(q_{6}\right)$ is associated with the annular member of the device (yellow part in Figure 1 (b)) in order to study the detailed dynamics of its internal components. The coil spring is modeled with a lumped constant stiffness parameter $\left(K_{h c}\right)$. The elastic force generated by the gas spring is described by a non-linear function. It is worth noting, however, that the gas spring is designed to exhibit linear behavior for the actual suspension stroke (hence, the constant stiffness $K_{h g}$ being adopted for the simulations). The dissipative effects characterizing the oil circuit, as well as a damper arranged in parallel to the two springs (Figure 1 (b)), are modeled by using lumped constant damping parameters $\left(C_{h o}\right.$ and $C_{h d}$, respectively). Friction (including stiction phenomena) related to the cylinder seals of the annular oil chamber, as well as between the gas and the oil chambers, is also considered by using a Coulomb model.

The values of the parameters adopted in the models are consistent with the characteristic of naked bikes. The rear suspension model reproduces the features of a cantilever-type mono-shock swing-arm. The most relevant parameters, and the corresponding values adopted for the numerical simulations, are reported in Table 1. 
Table 1. Main geometrical, mass and suspension parameters of the motorcycle models.

\begin{tabular}{|c|c|c|}
\hline Parameter & value & \\
\hline wheelbase & 1459.5 & $\mathrm{~mm}$ \\
\hline rake & 23.7 & deg \\
\hline front trail (positive) & 112.0 & $\mathrm{~mm}$ \\
\hline front wheel radius & 316.0 & $\mathrm{~mm}$ \\
\hline rear wheel radius & 316.0 & $\mathrm{~mm}$ \\
\hline rider mass & 70.0 & $\mathrm{~kg}$ \\
\hline sprung mass (with rider) & 228.6 & $\mathrm{~kg}$ \\
\hline frame assembly inertia (with rider) & $5.0 \cdot 10^{7}$ & $\mathrm{~kg}^{*} \mathrm{~mm}^{\wedge} 2$ \\
\hline front unsprung mass & 15.0 & $\mathrm{~kg}$ \\
\hline fork assembly inertia & $5.0 \cdot 10^{5}$ & $\mathrm{~kg}^{*} \mathrm{~mm}^{\wedge} 2$ \\
\hline rear unsprung mass & 18.0 & $\mathrm{~kg}$ \\
\hline swing-arm assembly inertia & $6.0 \cdot 10^{5}$ & $\mathrm{~kg}^{*} \mathrm{~mm}^{\wedge} 2$ \\
\hline$K_{s f}$ & 16.0 & $\mathrm{kN} / \mathrm{m}$ \\
\hline$C_{s f}$ & 0.74 & $\mathrm{kN} \cdot \mathrm{s} / \mathrm{m}$ \\
\hline front suspension stroke & 150.0 & $\mathrm{~mm}$ \\
\hline$K_{s r}$ & 80.0 & $\mathrm{kN} / \mathrm{m}$ \\
\hline$C_{s r}$ & 2.34 & $\mathrm{kN} \cdot \mathrm{s} / \mathrm{m}$ \\
\hline rear suspension stroke & 57.0 & $\mathrm{~mm}$ \\
\hline$K_{t f}$ & 180.0 & $\mathrm{kN} / \mathrm{m}$ \\
\hline$K_{t r}$ & 180.0 & $\mathrm{kN} / \mathrm{m}$ \\
\hline
\end{tabular}

\section{Simulated Conditions}

Firstly, the modal parameters of the in-plane vibration modes were evaluated by linearization around different operating positions (i.e. various suspension sag values), as they are expected to vary with the system configuration [44, 45]. The natural frequencies and the damping ratios were computed in static conditions, by imposing values of the rider sag between $50 \mathrm{~mm}$ (i.e. rider sag at the static equilibrium) and 110 $\mathrm{mm}$.

Dynamic simulations of three road conditions are then performed, namely random noise excitation, motorcycle passing over a speed bump, and vehicle passing over a pothole, for different constant running speed values in the range $10-60 \mathrm{~m} / \mathrm{s}$. The displacement input functions adopted for the first condition replicate different road roughness classes, according to the standard ISO 8608 [46]. The road input functions are synthesized as random noise excitations [47]. The road profiles adopted for the simulations are reported in Figure 4. The three road profiles, namely ISO B-C, C-D and D-E class profiles, will be referred to hereinafter as Road 1, Road 2 and Road 3, respectively. Although Road 3 may appear too rough for a running speed of $60 \mathrm{~m} / \mathrm{s}$, it 
was considered for revealing and emphasizing critical phenomena possibly characterizing the $A T$ model.

For the second and the third test conditions, idealized bump and pothole profiles described by $5^{\text {th }}$ degree polynomials are defined. A fixed length of $0.6 \mathrm{~m}$ and different height/depth values (range 0.05-0.10 m) are considered. The highest bump and the deepest pothole adopted in simulations are shown in Figure 5.

As for the $A T$ model, three different values of the gas-spring hydraulic preload (namely $2.5,3.0$ and $3.5 \mathrm{kN}$ ) are considered for the simulations. The dynamic response of the motorcycle is primarily analyzed in terms of two aspects, namely the vehicle handling performance and the riding comfort. The former aspect is assessed by considering the trend of the vertical forces acting between road and tires (namely, the magnitudes of the two visco-elastic forces modelling the tire contacts, simply referred to as tire forces hereafter) as a performance indicator of the traction (rear wheel) and breaking (front wheel) capabilities. The latter property is evaluated by analyzing the velocities exhibited by three locations of the sprung mass that are in contact with the rider (namely saddle, handlebar and footrests), in terms of trend in the time domain, root mean square value (RMS), kurtosis and frequency content. While the RMS measures vibration levels, the kurtosis (namely, the fourth standardized moment) is expected to provide an indication on the presence of significant spikes in the velocity signal, which may negatively affect comfort as well.

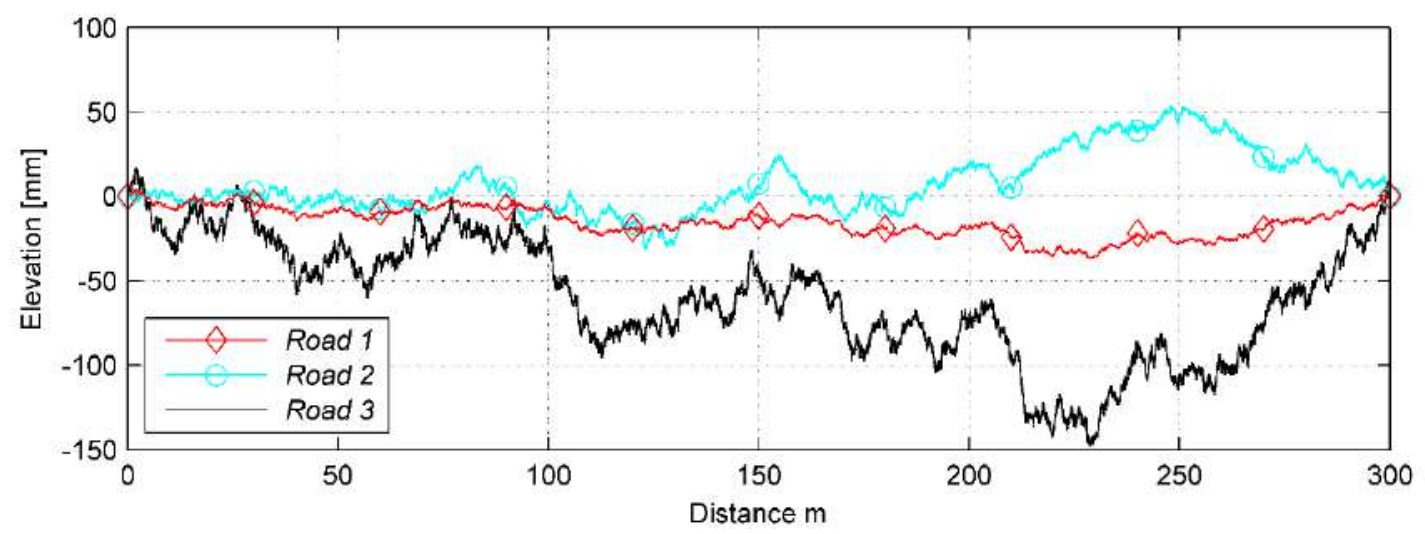

Figure 4. Simulated road profiles.
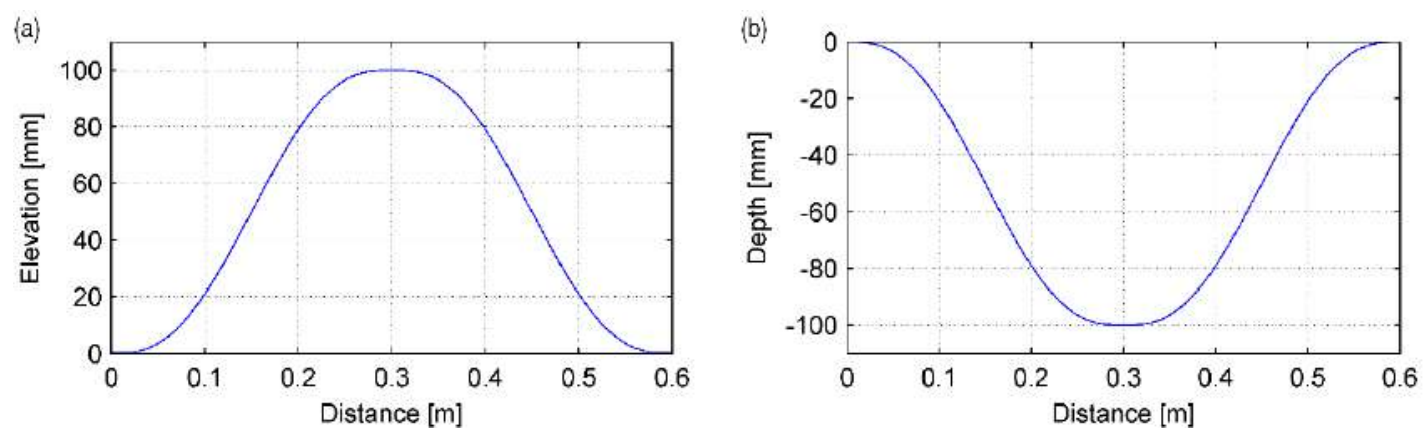

Figure 5. Examples of (a) bump and (b) pothole profiles. 


\section{RESULTS AND DISCUSSION}

\section{In-plane Modes}

The four motorcycle in-plane modes and natural frequencies, of both the $S T$ and the $A T$ (with preload of $3 \mathrm{kN}$ ), computed for the rider sag at static equilibrium (about $50 \mathrm{~mm}$, Sag 1) and for an imposed sag of $90 \mathrm{~mm}$ ( $\mathrm{Sag}$ 2), are reported in Table 2. A small increment in the first natural frequency is observed for the $S T$, since the cantilever swing-arm induces a slightly progressive behavior of the rear suspension. As for the AT, the effects of the non-linear suspension are clearly observed. The stiffness of the hydropneumatic suspension significantly decreases when the gas spring starts deflecting, hence causing a remarkable reduction in all the resonances. The high resonance frequency associated with the Sag 1 in the hydro-pneumatic system (AT) may appear associated with high-frequency vibrations under random road inputs and, in general, with high vertical velocities/accelerations of the suspended mass. However, due to the strong reduction in resonance frequency under compression, a different behavior under dynamic forcing is expected.

Table 2. In-plane natural frequencies.

\begin{tabular}{lrrrr}
\hline \multirow{2}{*}{ Vibration mode } & \multicolumn{4}{c}{ Frequency [Hz] } \\
\cline { 2 - 5 } & \multicolumn{3}{c}{ ST } & \multicolumn{3}{c}{$A T$} \\
\cline { 2 - 5 } & 1.76 & Sag 2 & Sag 1 & Sag 2 \\
\hline bounce & 2.48 & 2.46 & 3.17 & 1.35 \\
pitching & 15.38 & 15.40 & 16.10 & 2.32 \\
rear wheel hop & 16.03 & 15.99 & 16.15 & 16.08 \\
front wheel hop & & &
\end{tabular}

\section{Road Random Input}

Figure 6 shows the vertical contact force between the rear tire and the road as a function of time for the $A T$ with a preload of $3 \mathrm{kN}$ and two simulated conditions, chosen as examples. This quantity is adopted in order to evaluate the actual grip of the rear tire. In particular, a value of $33 \%$ of the contact force computed in static equilibrium (about $1370 \mathrm{~N}$ ) is defined as an arbitrary threshold for poor grip conditions.
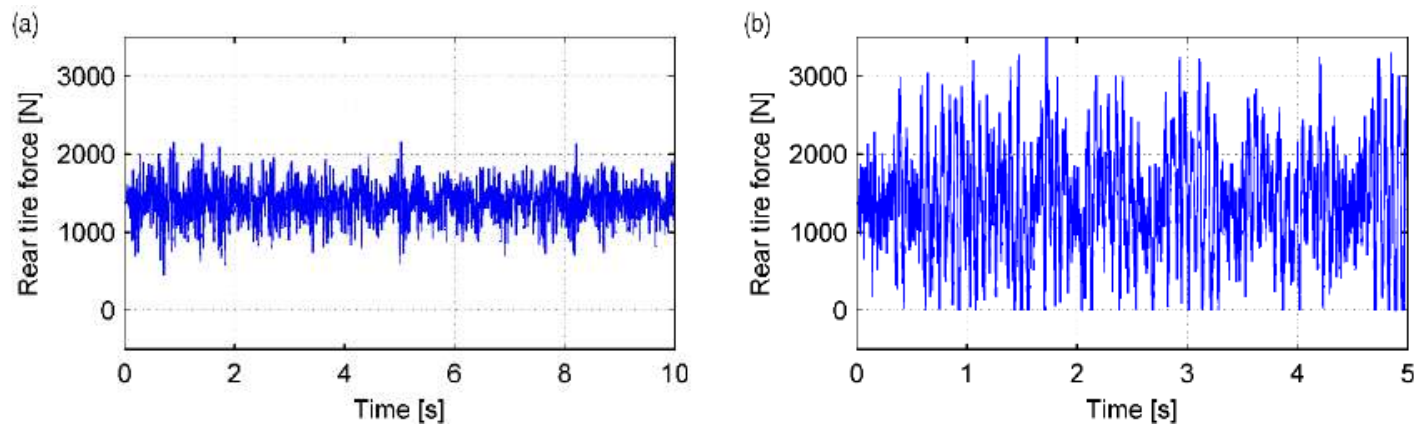

Figure 6. Rear tire force over time of the $A T$ (preload $3 \mathrm{kN}$ ) for (a) Road 1 at $30 \mathrm{~m} / \mathrm{s}$ and; (b) Road 2 at $60 \mathrm{~m} / \mathrm{s}$. 
The percentage of simulation time for which the contact force drops below the chosen limit (referred to as grip time reduction) is shown in Figure 7. In addition, the percentage of simulation time exhibiting null contact force (thus indicating lift-off of the rear wheel), is reported in Figure 8. Since no lift-off is observed for Road 1 input, the corresponding plot is omitted.

The results are basically consistent for all the simulated conditions, the only partial exceptions being the ones related to Road 1. However, the results reported in Figure 7 (a) are not considered significant for assessing grip, since extremely low values are experienced. In all the other cases the $A T$ system exhibits a remarkably lower fraction of time with reduced grip than the standard suspension, regardless of the value of the hydraulic preload. This is particularly evident for the results concerning the wheel lift-off (Figure 8). Moreover, in general a better grip is apparently achieved by increasing the hydraulic preload, which corresponds to an overall stiffer suspension.
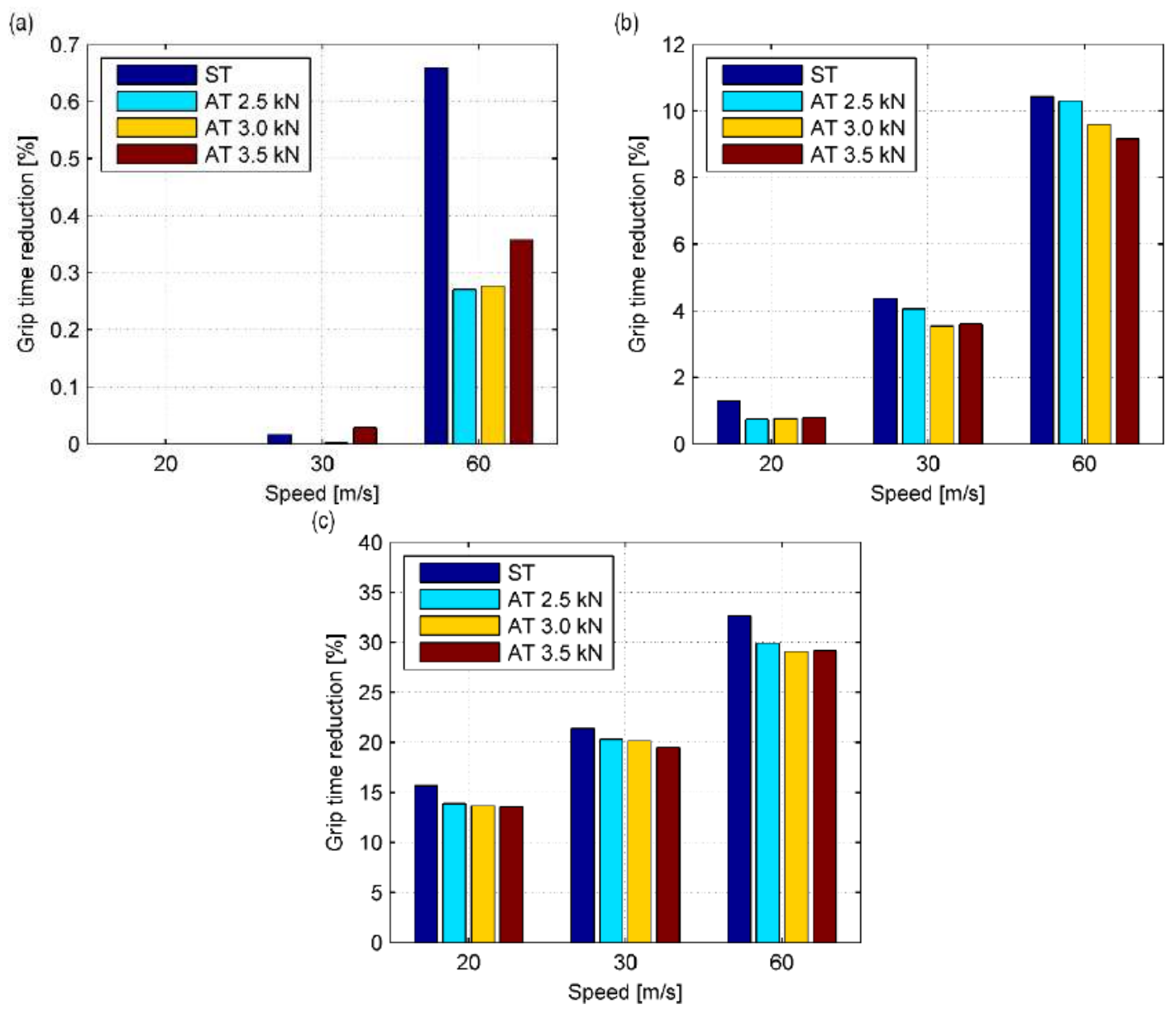

Figure 7. Percentage of simulation time with rear tire force below the defined limit for (a) Road 1, (b) Road 2 and; (c) Road 3. 

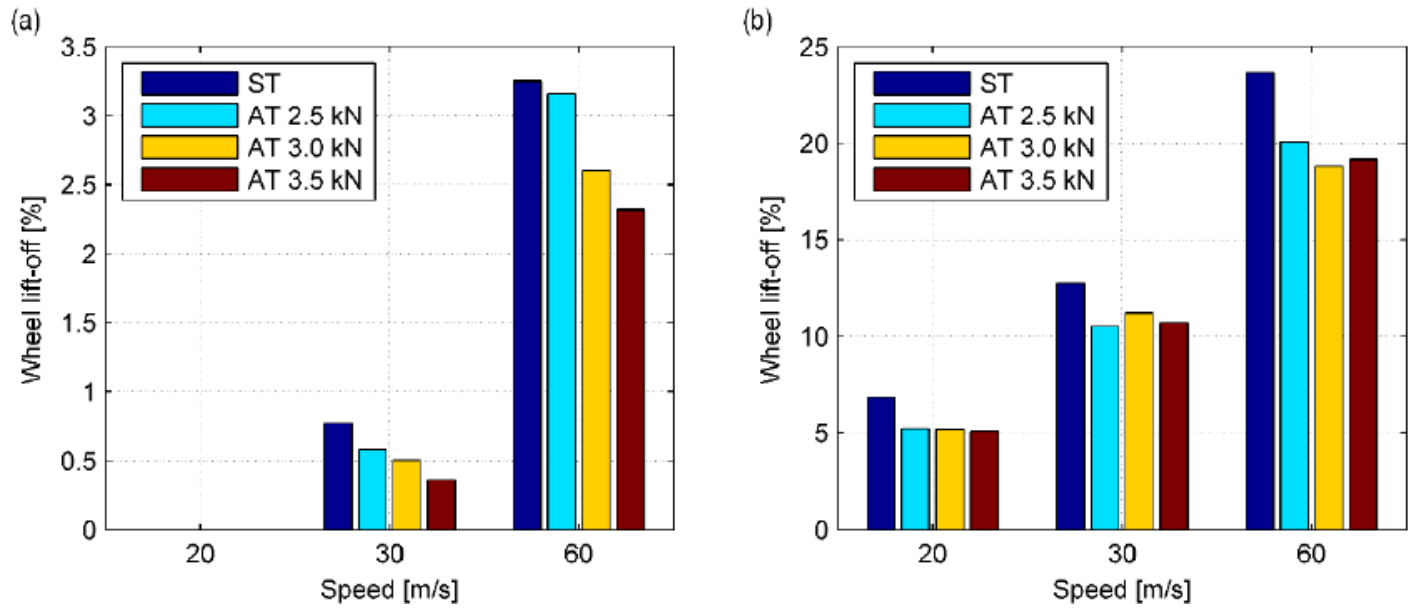

Figure 8. Percentage of simulation time with lift-off of the rear wheel for (a) Road 2, (b) Road 3.

The vertical velocity of the motorcycle saddle, $v_{s}$, as a function of time for the $A T$ with a preload of $3 \mathrm{kN}$ and two simulated conditions, chosen as examples, is shown in Figure 9 (a) and (b). This quantity is adopted to assess the riding comfort. The RMS value of $v_{s}$, normalized with respect to the RMS value of the velocity of the input road profile, is reported in Figure 10 (a) to (c).

The results are consistent for all tested road profiles. As the speed increases, the normalized RMS reduces for all models. Indeed, a higher forward velocity causes excitation to exhibit higher frequencies, thus affecting lesser the dynamics of the sprung mass (its resonances being characterized by rather low frequencies).

These results show that an increment in the hydraulic preload generates a growth in the saddle vertical velocity, thus penalizing comfort. However, despite the considerably higher resonance frequency at equilibrium, the comfort level observed for the $A T$ system seems comparable to that of the standard suspension.

The kurtosis of $v_{s}$ is reported in Figure 11 (a) to (c). The analysis of such parameter does not reveal a clear pattern for the $A T$, but the $S T$ experiences the same behavior. Hence, it does not mean that the $A T$ causes a worse comfort. Further simulations with smaller speed step are required to obtain a wider database. To sum up, the simulations with random road input confirmed the hydro-pneumatic suspension system as a potentially promising device. In particular, the intermediate value of hydraulic preload seems to provide the better compromise between grip and comfort.
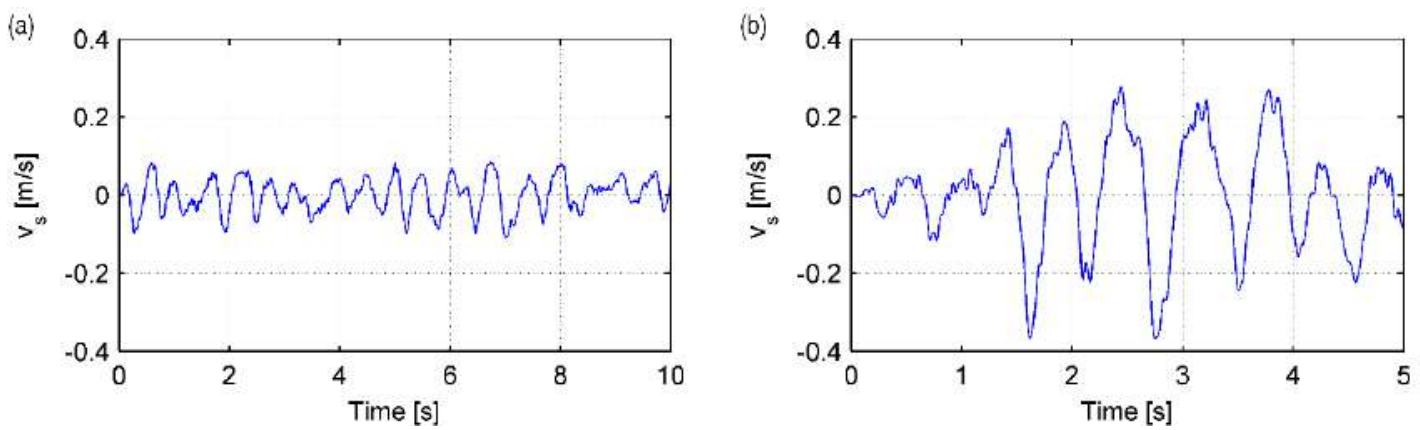

Figure 9. Saddle velocity over time of the $A T$ (preload $3 \mathrm{kN}$ ) for (a) $\operatorname{Road} 1$ at $30 \mathrm{~m} / \mathrm{s}$, (b) Road 2 at $60 \mathrm{~m} / \mathrm{s}$. 


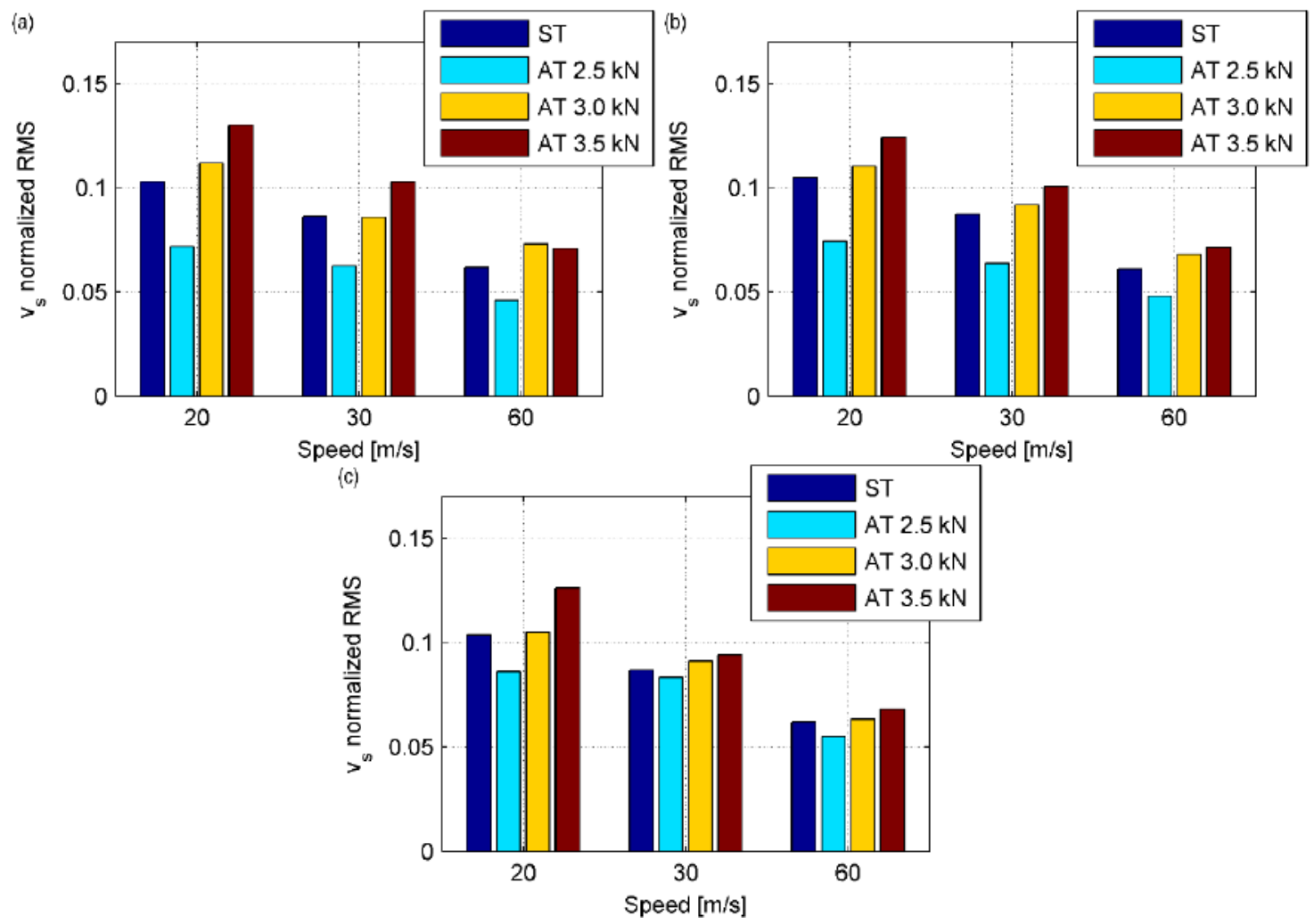

Figure 10. Normalized RMS value of the saddle velocity, $v_{s}$, for (a) Road 1, (b) Road 2, (c) Road 3.

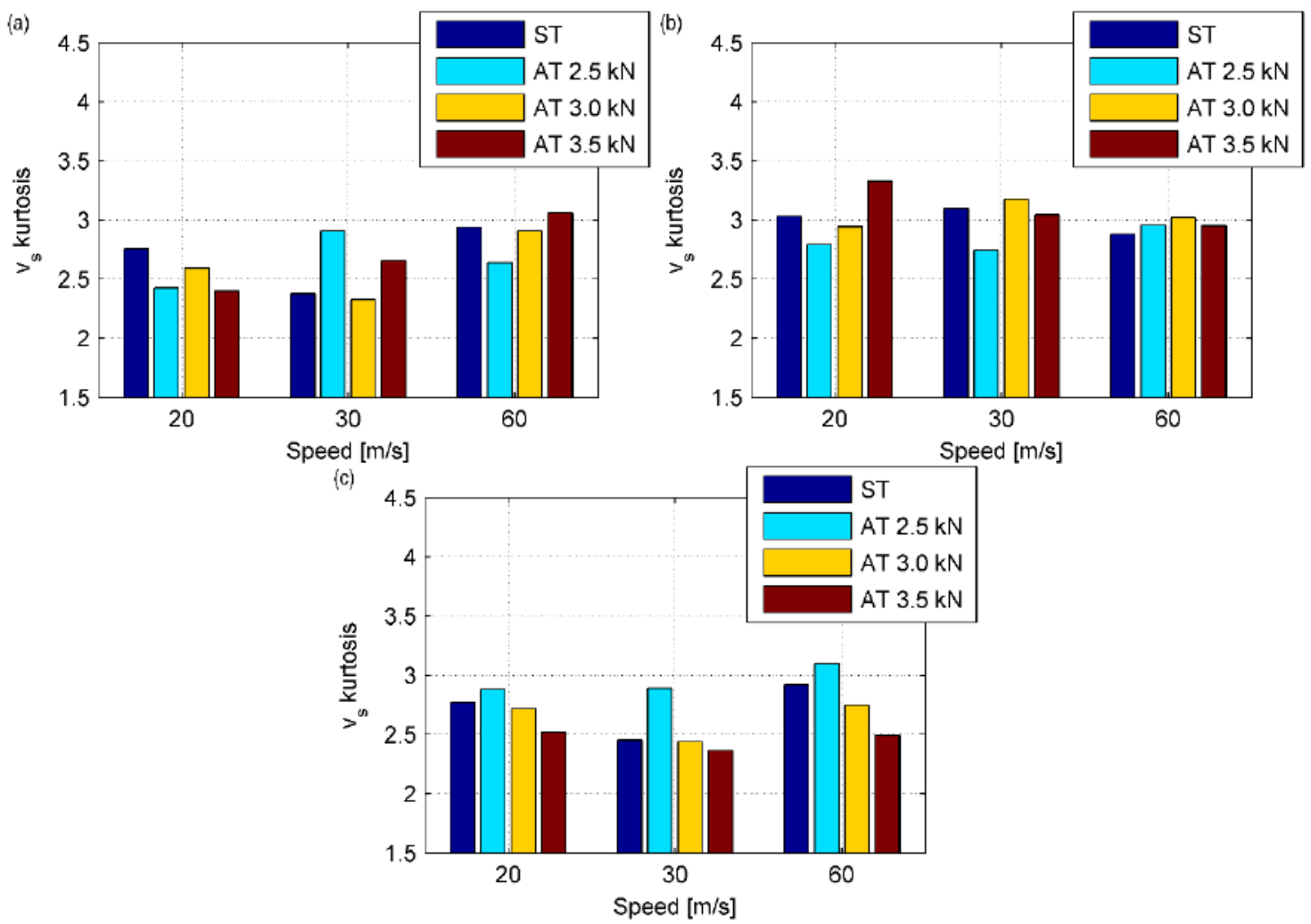

Figure 11. Kurtosis of the saddle velocity of the saddle velocity, $v_{s}$, for (a) Road 1, (b) Road 2, (c) Road 3. 


\section{Motorcycle Passing Over a Speed Bump}

Figure 12 (a) to (d) show the motorcycle dynamic response to the highest bump at 60 $\mathrm{m} / \mathrm{s}$, in terms of rear tire force as a function of time, for the $S T$ and the $A T$ (with all the preloads). For the sake of clarity, each curve is reported in a separate chart. A force peak slightly exceeding $12 \mathrm{kN}$ and occurring in all cases at about $0.03 \mathrm{~s}$ is not entirely reported in the figures for a better readability. It is worth recalling that the minimum magnitude of the tire force is zero, such value being exhibited when a complete lift-off of the wheel occurs.

The $A T$ model with the lowest preload behaves much differently from the $S T$ one; the tire force curves of the two models become more similar as the preload increases. In general, the $A T$ model exhibits a faster damping of the lower frequencies. It also provides a reduction in the wheel lift-off time; the best performance being achieved for the $3 \mathrm{kN}$ preload (about $-16 \%$ ).

The saddle velocity curves related to the simulation results reported in Figure 12 are shown in Figure 13 (a) and (b). The velocity values are comparable except for the first oscillation, which has a greater amplitude in the $A T$ (particularly for the lowest preload value). In addition, these results confirm the faster attenuation of the lowfrequency oscillations in the AT model.

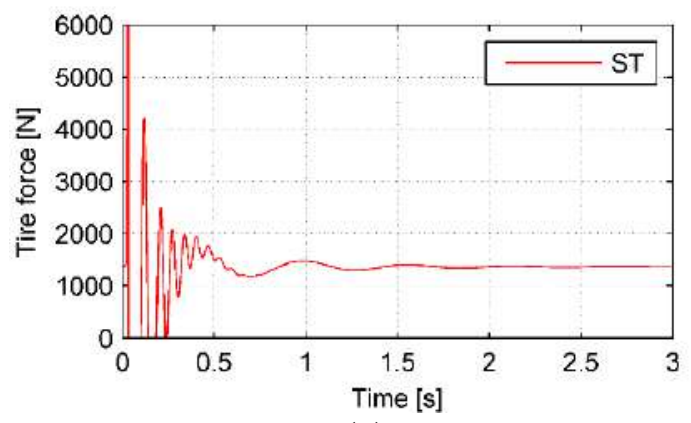

(a)

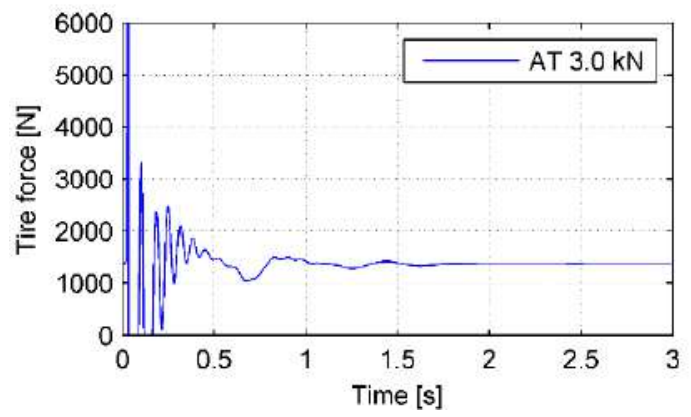

(c)

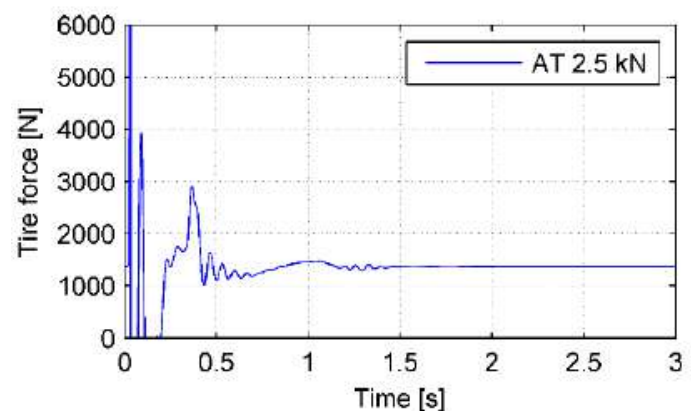

(b)

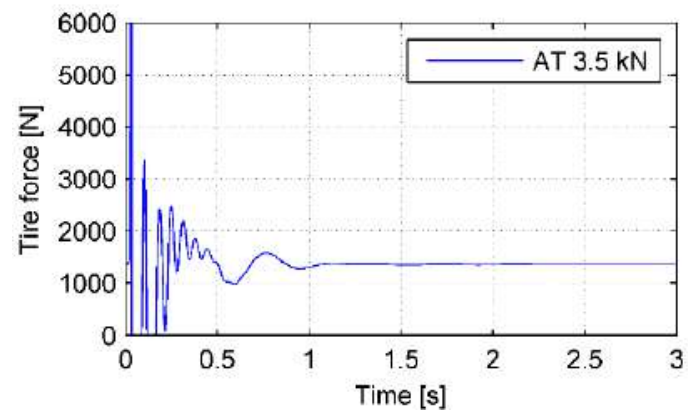

(d)

Figure 12. Rear tire force over time of (a) $S T$, and $A T$ at (b) $2.5 \mathrm{kN}$, (c) $3.0 \mathrm{kN}$ and; (d) $3.5 \mathrm{kN}$ preload for the $0.1 \mathrm{~m}$ bump at $60 \mathrm{~m} / \mathrm{s}$. 


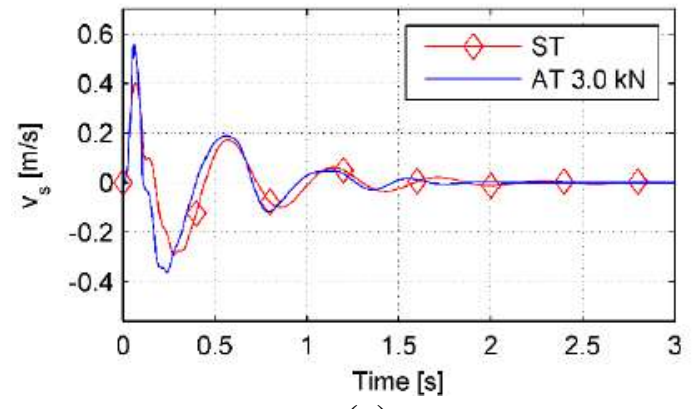

(a)

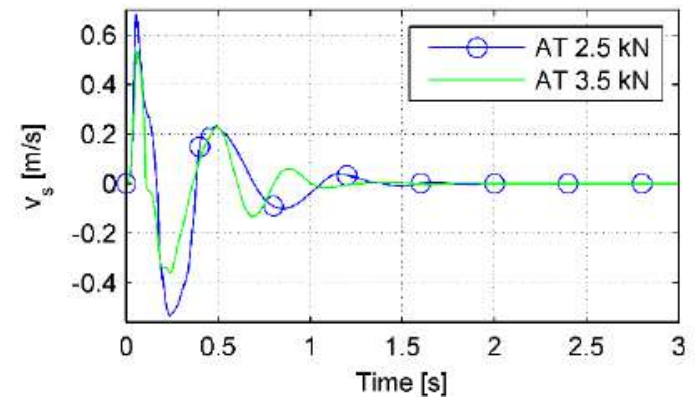

(b)

Figure 13. Saddle velocity over time of (a) $S T$ and $A T-3.0 \mathrm{kN}$, (b) $A T-2.5 \mathrm{kN}$ and $A T-3.5$ $\mathrm{kN}$ for the $0.1 \mathrm{~m}$ bump at $60 \mathrm{~m} / \mathrm{s}$.

As for the other two speed values tested with the $0.1 \mathrm{~m}$ bump, Figure 14 (a) and (b) show the comparison between the rear tire forces computed in the $S T$ and the $A T$ (preload $3 \mathrm{kN}$ ) for the $30 \mathrm{~m} / \mathrm{s}$ simulation, chosen as an example (peaks of about $11 \mathrm{kN}$ at $0.057 \mathrm{~s}$ non-entirely shown for a better readability).

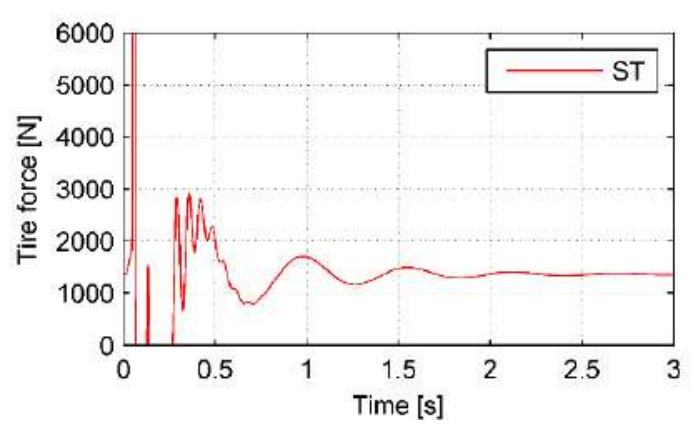

(a)

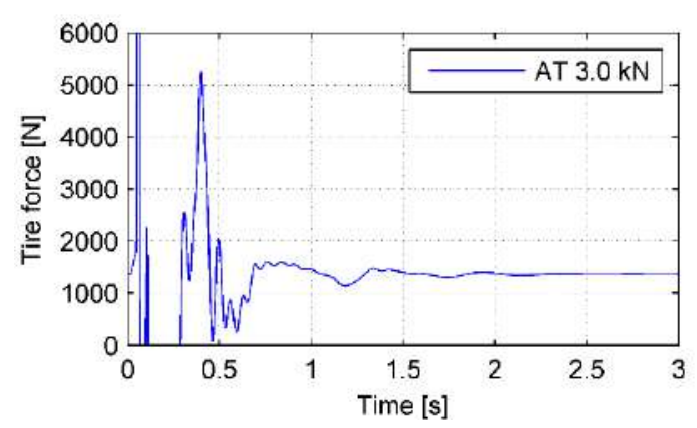

(b)

Figure 14. Rear tire force over time of the (a) $S T$, (b) $A T$ with3.0 kN. Preload and $0.1 \mathrm{~m}$ bump at $30 \mathrm{~m} / \mathrm{s}$.

An unexpected peak of the tire force can be observed after the second wheel rebound for the $A T$ model (about $0.4 \mathrm{~s}$ ). Such abrupt force increment is caused by the suspension rod reaching its full stroke and hitting the bump-stop (characterized by a stiffness that is about ten times the spring rate of the coil spring). This conclusion is supported by the analysis of the elastic force generated by the bump-stop (Figure 15), which reveals a relevant peak at about $0.4 \mathrm{~s}$.

The dynamic response of the sprung mass is only marginally affected by the observed force spike. Figure 16 (a) shows the comparison between the saddle velocities computed with the same conditions considered for the data reported in Figure 14. The $A T$ exhibits a steeper curve (i.e. a greater acceleration) when the spike occurs $(0.4 \mathrm{~s})$, but the velocity values are globally comparable.

It is worth noting that another spike occurs in the bump-stop force at the very beginning of the simulations, at about $0.072 \mathrm{~s}$ (for the sake of readability, the peak of about $15 \mathrm{kN}$ is not entirely shown in the chart). However, the $S T$ model also experiences the same phenomenon, so that both models have a very similar initial behavior.

The saddle velocities for the simulations at $30 \mathrm{~m} / \mathrm{s}$ are investigated in the frequency domain by computing the Power Spectral Density (PSD), reported in Figure 
16 (b). The analysis shows that for both models the frequency content is ascribable to the first two vibration modes, i.e. the bounce and the pitching modes, although a wide peak is observed instead of two distinct ones. Indeed, in the $S T$ model the frequencies are very close, and leakage is present (also because of the transient signal). As for the $A T$ model, the peak extends approximately from 1.4 to $3.2 \mathrm{~Hz}$, thus confirming a variation of the resonances during the simulation, as expected.

To sum up, the bump input simulations revealed some potential benefits and drawbacks of the hydro-pneumatic suspension system and provided essential information for a possible improvement of the device. An increment in its total stroke appears advisable.

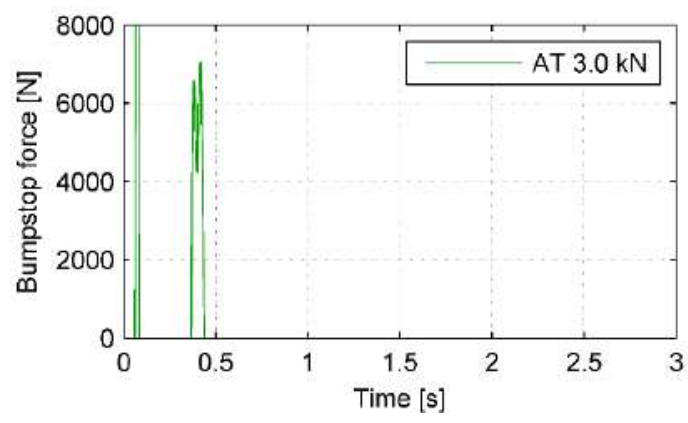

Figure 15. Bump-stop force over time of the AT (preload $3 \mathrm{kN}$ ), $0.1 \mathrm{~m}$ bump at $30 \mathrm{~m} / \mathrm{s}$.
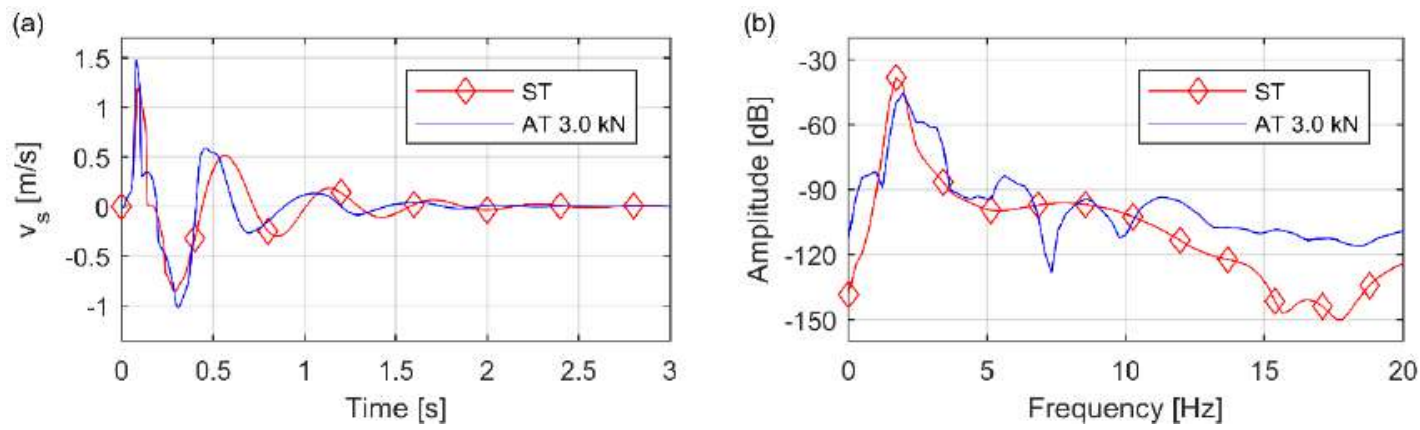

Figure 16. Saddle velocity of the ST and the AT (preload $3 \mathrm{kN}$ ) for the $0.1 \mathrm{~m}$ bump at $30 \mathrm{~m} / \mathrm{s}$ (a) time history, (b) PSD (reference $1 \mathrm{~m} / \mathrm{s}$ ).

\section{Motorcycle Passing Over a Pothole}

Figures 17 and 18 (a) show the dynamic response of the $S T$ and the $A T$ (preload $3 \mathrm{kN}$ ) to the deepest pothole at $30 \mathrm{~m} / \mathrm{s}$, in terms of rear tire force and saddle velocity, respectively, as functions of time. The trends of the tire force are very similar, the oscillations being slightly smaller for the $A T$. The same behavior is observed for all tested conditions. As for the saddle velocity, the signals exhibit additional vibrations with higher frequencies with respect to the case of the speed bump. The PSD in Figure 18 (b) confirms that in both models the frequency content is mainly ascribable to the first two vibration modes. However, unlike for the bump simulations, also the third resonance is excited (corresponding to the rear wheel hop mode). Some differences between the models can be appreciated in terms of amplitude of the response. Nonetheless, since the velocity values remain very small, the results are not considered sufficiently reliable to properly assess the performance of the hydro-pneumatic 
suspension and performing further simulations with rougher pothole profiles seems advisable.

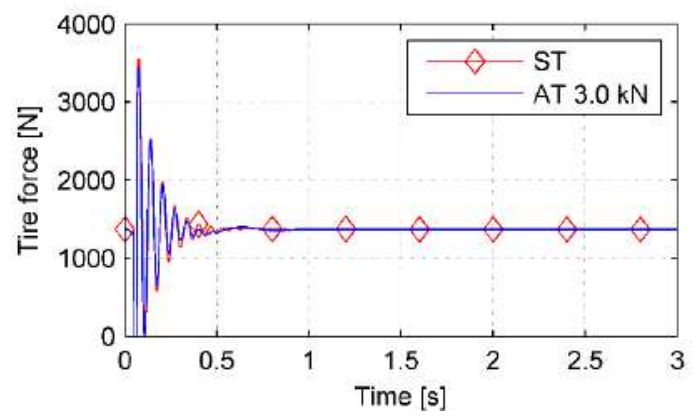

Figure 17. Rear tire force over time of the $S T$ and the $A T$ (preload $3 \mathrm{kN}$ ) for the $0.1 \mathrm{~m}$ pothole at $30 \mathrm{~m} / \mathrm{s}$.
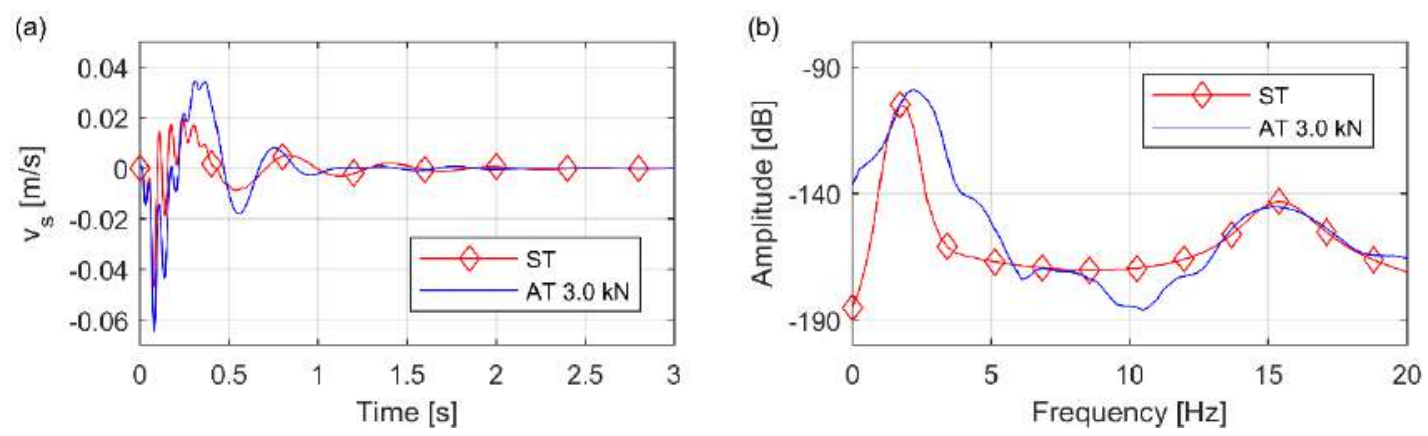

Figure 18. Saddle velocity of the $S T$ and the $A T(\operatorname{preload} 3 \mathrm{kN})$ for the $0.1 \mathrm{~m}$ pothole at $30 \mathrm{~m} / \mathrm{s}$ : (a) time history, (b) PSD (reference $1 \mathrm{~m} / \mathrm{s}$ ).

\section{CONCLUSION}

A numerical investigation of a road motorcycle equipped with a new hydro-pneumatic rear suspension with strong non-linear behavior was carried out by means of multibody models and simulations. The study focused on the in-plane dynamics, and in particular on the comparison with the dynamic response of the same motorcycle equipped with a standard suspension featuring linear spring rate.

The numerical results confirmed the potential benefits of the innovative device. In particular the simulations showed that an enhancement of the grip (in terms of reduction in load fluctuations on the rear wheel) can be achieved, while keeping basically unaltered the comfort level with respect to the standard suspension (notwithstanding the higher resonance frequency at static equilibrium). In addition, the hydro-pneumatic suspension exhibited high sensitivity to the hydraulic preload, thus such parameter appearing a key factor to develop optimization strategies. Finally, the analysis provided some useful hints for possibly enhancing the suspension design. In the future steps of the research the dynamic response of under different conditions, such as breaking and cornering, can be assessed. 


\section{ACKNOWLEDGEMENT}

Federico Giuliani from Umbria Kinetics (Foligno, Italy) is kindly acknowledged for providing realistic data for the simulations.

\section{REFERENCES}

[1] Sharp RS, Crolla DA. Road Vehicle Suspension System Design - a review. Vehicle System Dynamics. 1987; 16(3): 167-192.

[2] Gillespie TD. Fundamentals of Vehicle Dynamics. Warrendale: SAE International; 1992.

[3] Popp K, Schiehlen W. Ground Vehicle Dynamics. Berlin Heidelberg: SpringerVerlag; 2010.

[4] Dixon JC. Suspension Geometry and Computation. Chichester: John Wiley \& Sons; 2009.

[5] Elbeheiry EM, Karnopp DC, Elaraby ME, Abdelraaouf AM. Advanced Ground Vehicle Suspension Systems - A Classified Bibliography. Vehicle System Dynamics. 1995; 24(3): 231-258.

[6] Zamzamzadeh M, Saifizul AA, Ramli R, Soong MF. Dynamic simulation of brake pedal force effect on heavy vehicle braking distance under wet road conditions. International Journal of Automotive and Mechanical Engineering. 2016; 13(3): 3555-3563.

[7] Pavlovic A, Fragassa C. General considerations on regulations and safety requirements for quadricycles. International Journal for Quality Research. 2015; 9(4): 657-674.

[8] Elkady M, Elmarakbi A, MacIntyre J. Integration of vehicle dynamics control systems with an extendable bumper for collision mitigation. International Journal of Automotive and Mechanical Engineering. 2015; 12: 2893-2913.

[9] Vannucchi de Camargo F, Fragassa C, Pavlovic A, Martignani M. Analysis of the Suspension Design Evolution in Solar Cars. FME Transactions. 2017; 45(3): 394-404.

[10] Minak G, Fragassa C, Vannucchi de Carmago F. A Brief Review on Determinant Aspects in Energy Efficient Solar Car Design and Manufacturing. In: Campana G, Howlett R, Setchi R, Cimatti B, editors. Sustainable Design and Manufacturing 2017. SDM 2017. Smart Innovation, Systems and Technologies, Vol. 68, Cham: Springer, 2017, p 847-856.

[11] Hu Y, Chen MZQ, Shu Z. Passive vehicle suspensions employing inerters with multiple performance requirements. Journal of Sound and Vibration. 2014; 333: 2212-2225.

[12] Hua Y, Chen MZQ, Sun Y. Comfort-oriented vehicle suspension design with skyhook inerter configuration. Journal of Sound and Vibration. 2017; 405: 3447.

[13] Concilio A, De Simone MC, Rivera ZB, Guida D. A New Semi-Active Suspension System for Racing Vehicles. FME Transactions. 2017; 45(4): 578584.

[14] Azraai MR, Priyandoko G, Yusoff AR, Rashid MFFA. Parametric optimization of magneto-rheological fluid damper using particle swarm optimization. International Journal of Automotive and Mechanical Engineering. 2015; 11: 2591-2599. 
[15] Chen S-A, Wang J-C, Yao M, Kim Y-B. Improved optimal sliding mode control for a non-linear vehicle active suspension system. Journal of Sound and Vibration. 2017; 395: 1-25.

[16] Zulkarnain N, Zamzuri H, Mazlan SA. Ride and handling analysis for an active anti-roll bar: case study on composite nonlinear control strategy. International Journal of Automotive and Mechanical Engineering. 2014; 10: 2122-2143.

[17] Cossalter V. Motorcycle Dynamics. 2nd ed. LULU; 2006.

[18] Noriega A, Mántaras DA, Blanco D. Kinetostatic benchmark of rear suspension systems for motorcycle. In: Petuya V, Pinto C, Lovasz EC, editors. New Advances in Mechanisms, Transmissions and Applications. Mechanisms and Machine Science, Vol. 17, Dordrecht: Springer, 2014, p 1-8.

[19] Sharma A, Limebeer DJN. Motorcycle suspension design using matrix inequalities and passivity constraints. Vehicle System Dynamics. 2012; 50(3): 377-393.

[20] Sharp RS, Limebeer DJN. A Motorcycle Model for Stability and Control Analysis. Multibody System Dynamics. 2001; 6(2): 123-142.

[21] Pennestrì E, Strozzieri A. Optimal design and dynamic simulation of a motorcycle with linkage suspension. International Journal of Vehicle Design. 1988; 9(3): 339-350.

[22] Moreno-Ramírez C, Tomas-Rodríguez M, Evangelou SA. Dynamical Analysis of a Duolever Suspension System. In: 2012 UKACC International Conference on Control, Cardiff, UK, pp. 1106-1111; 2012.

[23] Barbagallo R, Sequenzia G, Cammarata A, Oliveri SM, Fatuzzo G. Redesign and multibody simulation of a motorcycle rear suspension with eccentric mechanism. International Journal on Interactive Design and Manufacturing. 2018; 12(2): 517-524. DOI:10.1007/s12008-017-0402-3

[24] Moreno-Ramírez C, García-Fernández P, de-Juan A, Tomas-Rodríguez M. Interconnected Suspension System on Sport Motorcycles. In: Petuya V, Pinto C, Lovasz EC, editors. New Advances in Mechanisms, Transmissions and Applications. Mechanisms and Machine Science, Vol. 17, Dordrecht: Springer, 2014, p 9-16.

[25] Moreno-Ramírez C, Tomas-Rodríguez M. Non-linear optimization of a sport motorcycle's suspension interconnection system. In: 2014 UKACC International Conference on Control, Loughborough, UK, pp. 319-324; 2014.

[26] Spelta C, Savaresi SM, Fabbri L. Experimental analysis of a motorcycle semiactive rear suspension. Control Engineering Practice. 2010; 18(11), 1239-1250.

[27] Chen C, Chan YS, Zou L, Liao W-H. Self-powered magnetorheological dampers for motorcycle suspensions. Proceedings of the Institution of Mechanical Engineers, Part D: Journal of Automobile Engineering. 2018; 232(7), 921-935.

[28] Gogo K, Fuse T, Uchiyama M, Adachi E, Honda T. Rear-wheel suspension for two-wheeled vehicle. Patent: EP1816063A2; 2007.

[29] Trethewey,M. Motorcycle suspension system. Patent: US8403092B1; 2013.

[30] Giuliani F, Bellani G. Suspension for wheeled vehicle. Patent: WO2015/155712A1; 2015.

[31] Martini A, Bellani G. Numerical Investigation on the Dynamics of a HighPerformance Motorcycle Equipped with an Innovative Hydro-Pneumatic Suspension System. In: $8^{\text {th }}$ ECCOMAS Thematic Conference on Multibody Dynamics, Prague, Czech Republic, pp. 719-725; 2017. 
[32] Barethiye VM, Pohit G, Mitra A. Analysis of a quarter car suspension system based on nonlinear shock absorber damping models. International Journal of Automotive and Mechanical Engineering. 2017; 14(3): 4401-4418.

[33] Thite AN, Coleman F, Doody M, Fisher N. Experimentally validated dynamic results of a relaxation-type quarter car suspension with an adjustable damper. Journal of Low Frequency Noise, Vibration and Active Control. 2017; 36(2): 148-159.

[34] Shabana AA. Dynamics of multibody systems. Cambridge: Cambridge University Press; 2013.

[35] Pappalardo CM, Guida D. On the use of two-dimensional Euler parameters for the dynamic simulation of planar rigid multibody systems. Archive of Applied Mechanics. 2017; 87(10): 1647-1665.

[36] Pappalardo CM. A natural absolute coordinate formulation for the kinematic and dynamic analysis of rigid multibody systems. Nonlinear Dynamics. 2015; 81(4): 1841-1869.

[37] Wu L, Zhang W-J. Hierarchical modeling of semi-active control of a full motorcycle suspension with six degrees of freedoms. International Journal of Automotive Technology. 2010; 11(1), 27-32.

[38] Sharp RS, Evangelou S, Limebeer DJN. Advances in the Modelling of Motorcycle Dynamics. Multibody System Dynamics. 2004; 12(3): 251-283.

[39] Sequenzia G, Oliveri SM, Fatuzzo G, Calì M. An advanced multibody model for evaluating rider's influence on motorcycle dynamics. Proceedings of the IMechE, Part K: Journal of Multi-body Dynamics. 2015; 229(2): 193-207.

[40] Barbagallo R, Sequenzia G, Oliveri SM, Cammarata A. Dynamics of a highperformance motorcycle by an advanced multibody/control co-simulation. Proceedings of the IMechE, Part K: Journal of Multi-body Dynamics. 2016; 230(2): 207-221.

[41] Patel M, Orzechowski G, Tian Q, Shabana AA. A new multibody system approach for tire modeling using ANCF finite elements. Proceedings of the Institution of Mechanical Engineers, Part K: Journal of Multi-body Dynamics. 2016; 230(1): 69-84.

[42] Lot R. A motorcycle tire model for dynamic simulations: Theoretical and experimental aspects. Meccanica. 2004; 39(3): 207-220.

[43] Pacejka HB. Tire and Vehicle Dynamics. 3rd ed. Oxford: ButterworthHeinemann; 2012.

[44] Martini A, Troncossi M, Carricato M, Rivola A. Elastodynamic behavior of balanced closed-loop mechanisms: numerical analysis of a four-bar linkage. Meccanica. 2014; 49(3): 601-614.

[45] Martini A, Troncossi M, Rivola A. Elastodynamic effects of mass-balancing: experimental investigation of a four-bar linkage. Advances in Mechanical Engineering. 2013; 2013:949457.

[46] International Organization for Standardization. Mechanical vibration - Road surface profiles - Reporting of measured data. ISO 8608:2016.

[47] Agostinacchio M, Ciampa D, Olita S. The vibrations induced by surface irregularities in road pavements - a Matlab® approach. European Transport Research Review. 2014; 6(3): 267-275. 